\title{
CONTRIBUIÇÃO DO SISTEMA AMBIENTAL URBANO AO ESTUDO DA DENGUE EM IRANDUBA
}

\section{CONTRIBUTION OF THE URBAN ENVIRONMENTAL SYSTEM TO THE STUDY OF THE DENGUE IN IRANDUBA}

\author{
Rayane Brito de Almeida \\ Programa de Pós-Graduação em Geografia pela UFAM \\ rayanebritodealmeida@gmail.com \\ Marcela Beleza de Castro \\ Programa de Pós-Graduação em Geografia (PPG-GEO) da UFAM \\ marcelabelezah@gmail.com
}

\begin{abstract}
RESUMO
O presente texto objetivou identificar e analisar a formação de áreas vulneráveis ao risco de dengue produzido no espaço urbano de Iranduba a partir do Sistema Ambiental Urbano (SAU). As alterações na paisagem em decorrência da dinâmica espacial têm sido mais aceleradas, principalmente após a construção da ponte Rio Negro, impactando na valorização e desvalorização de solos urbanos, onde as enfermidades são identificadas, sobretudo nos moradores de baixa renda que moram, em sua grande parte, em áreas vulneráveis. Neste estudo foram realizados levantamentos bibliográficos, trabalho de campo e mapeamento das áreas. A problemática foi fundamentada no SAU, por se caracterizar pela abordagem sistêmica aos problemas socioambientais urbanos. Os resultados mostraram que as áreas vulneráveis ao risco de dengue são formadas em decorrência da constituição de moradias em áreas expostas as transformações ambientais, como a enchente; e em áreas com precariedades de estruturas urbanas, como a ineficácia e/ou ausência de saneamento básico (abastecimento de água, coleta de lixo, rede de esgoto) e serviços básicos como a saúde e educação ambiental, construindo particularidades de riscos e vulnerabilidades socioambientais à dengue no contexto urbano de Iranduba.
\end{abstract}

Palavras-chave: Sistema Ambiental Urbano. Dengue. Risco. Vulnerabilidade. Iranduba.

\begin{abstract}
The present text aimed to identify and analyze the formation of areas vulnerable to the risk of dengue produced in the urban space of Iranduba according Urban Environmental System (SAU). The changes in urban soil due to the spatial dynamics have been more accelerated, especially after the construction of the Rio Negro bridge, impacting the valorization and devaluation of urban soils, where the diseases are identified, especially in the low income residents who live in in vulnerable areas. In this study, bibliographical surveys were carried out regarding the subject studied, field work and area mapping. The problem was grounded in the Urban Environmental System (SAU) for being characterized as a systemic approach to urban socio-environmental problems. The results showed that areas vulnerable to dengue risk are formed due to the constitution of housing in areas exposed to environmental changes, such as flooding; and in areas with poor urban structures, such as inefficiency and / or lack of basic sanitation ( water supply, garbage collection, sewage network) and basic services such as health and environmental education, building particularities of social and environmental risks and vulnerabilities to dengue in the urban context of Iranduba.
\end{abstract}

Keywords: Urban Environmental System. Dengue. Risk. Vulnerability. Iranduba city.

\section{INTRODUÇÃO}

O uso e apropriação do solo urbano contêm diversas dinâmicas (econômicas, sociais e ambientais) como a busca de um lugar para morar e que, contraditoriamente, forma áreas de risco. Em meio às

Recebido em: 03/10/2018

Aceito para publicação em: 02/07/2019 
inúmeras situações vinculadas à qualidade de vida, a reprodução de áreas sem infraestrutura adequada tem ocasionado uma maior distribuição espacial do vetor transmissor da dengue, as quais segundo Barreto e Teixeira (2008), formam habitats potencializados ao desenvolvimento desta doença.

Mendonça (2003 e 2009) e Rocha (2013) apontam que o aumento e o desenvolvimento de doenças estão relacionados a diversos fatores: a contaminação do abastecimento de água, a precariedade dos serviços sanitários, variabilidade climática, que associados à urbanização sem infraestrutura adequada e a ineficácia de politicas públicas de saúde quanto à multicausalidade do processo saúdedoença, potencializam a reprodução de vetores e transmissores.

Segundo Nunes (2015), nos últimos anos a forma "rápida e insalubre" que ocorrem as ocupações é fator contribuinte para "o advento de desestruturações de todas as ordens", que se deflagram como riscos à sociedade. Além disso, o aumento da espacialidade urbana em decorrência da constante expansão demográfica em áreas sem ou com frágil infraestrutura fez com que demasiados problemas socioambientais urbanos se agravassem.

O espaço urbano se configura por desigualdades (econômicas, sociais, políticas, entre outras) nas quais os setores de baixa renda, em sua maior parte, se constroem longe dos centros decisórios de poder e mercado. E estas desigualdades se estruturam nas características das moradias, são diferenciadas espacialmente. Essa diferença pode inclusive ser uma segregação espacial, pois em alguns espaços há infraestrutura e serviços e em outros não, diversificando a paisagem da cidade mostrando as desigualdades da sociedade (CARLOS, 2008).

A infraestrutura é um elemento fundamental para o entendimento de uma unidade espacial urbanizada, assim como a sua concretude histórica no estudo de áreas vulneráveis as doenças. O desenvolvimento de doenças é diferenciado pelos contrastes sociais nas estruturas espaciais, onde as doenças são identificadas, sobretudo nos moradores de áreas vulneráveis.

A expansão da dengue apresenta um caráter multicausal, pois envolve dinâmicas sociais (produção de lixo não orgânico, ocupações de áreas com saneamento básico precário, capacitação dos agentes de saúde) e naturais (chuvas e temperaturas que propiciam condições favoráveis ao desenvolvimento do vetor) que juntos se articulam no meio urbano. As áreas urbanas se tornam vulneráveis pelo tipo de estrutura urbana que as constituem.

No que se refere aos danos após um fenômeno natural, Bandeira, Nunes e Lima (2016) apontam que chuvas extremas, por exemplo, contribuem ao agravo do risco a saúde, que é acentuado para as moradias que, na maioria das vezes, não possuem estruturas urbanas resilientes para sustentar tal evento. Estas estruturas urbanas não são resilientes devido, sobretudo, ao planejamento do espaço urbano, uma vez que o risco formado nas cidades é em decorrência quando a dinâmica natural (climática, hidrológica, etc.) se encontra com a dinâmica da sociedade.

Quanto ao risco de dengue, os gestores públicos de saúde não incorporam a multicausalidade dos fatores que inferem no desenvolvimento da dengue, uma vez que a formação de áreas vulneráveis a esta doença retrata a debilidade de serviços como a coleta de lixo, que "acumula" entulhos em lugares inapropriados e propiciam a (re) produção do vetor da dengue. Sobre o abastecimento de água, que para suprir a necessidade de consumo, a população fragilizada busca outros meios de obtenção e armazenamento de água, mas que muitas vezes é de forma inadequada, o que também propicia ambiente ideal ao vetor da dengue.

$O$ atrelamento entre as condições-modo de vida urbana encontra-se na gênese dos problemas ambientais urbanos, fato que os torna socioambientais (MENDONÇA, 2009a). Nesse contexto, este trabalho é analisado a partir da abordagem socioambiental de Mendonça (2004), que propôs o Sistema Ambiental Urbano (S.A.U.). Este permite uma abordagem integrada dos problemas urbanos advindos da interação sociedade (aspectos socioespaciais) e natureza (aspectos climáticos e ambiente ecológico do mosquito), como a dengue, por exemplo, vista como uma problemática interdisciplinar. Este mesmo método já foi aplicado em estudos sobre clima, urbanização e saúde, como em Paula (2005), Oliveira (2006), Aquino Junior (2010), Roseghini (2013), Beleza e Costa (2016; 2016a; 2017), Almeida e Costa (2016; 2016a; 2017), Dantas e Costa (2017).

Nos últimos seis anos, a cidade de Iranduba tem apresentado intensas alterações em suas paisagens, principalmente depois da construção da Ponte sobre o rio Negro que a interliga com a cidade de Manaus. A constituição de novas moradias, em sua maior parte, é sem infraestrutura 
adequada (SOUSA, 2013). O presente texto objetivou identificar e analisar as áreas vulneráveis ao risco de dengue em Iranduba a partir do S.A.U.

\section{MATERIAIS E MÉTODOS}

Os dados utilizados consistem em levantamento fotográfico, dados de notificações de dengue pelo Sistema de Notificação de Agravos (SINAN) e pela Secretaria Municipal de Saúde (SEMSA) de Iranduba. Também foram utilizados dados do IBGE (2010) em relação aos domicílios com água encanada, domicílios com abastecimento de água e esgoto sanitário inadequado, domicílios com coleta de lixo e renda per capita $(R \$)$. As informações de adensamento populacional foram obtidas na Secretaria de Estado de Planejamento e Desenvolvimento Econômico (SEPLAN). Para analisar o aumento da espacialidade urbana, foram utilizadas imagens de satélites do Landsat 5, disponibilizadas no catálogo de imagens do Instituto Nacional de Pesquisas Espaciais (INPE).

Para aplicar o S.A.U. neste estudo, foi necessário fazer um reconhecimento descritivo do sítio urbano em que se configura a área de estudo, ou seja, os aspectos físicos (subsistema natural) como, por exemplo, a topografia, característica climática e bacias hidrográficas urbanas. Em seguida, obtiveramse informações necessárias dos níveis de uso e ocupação (subsistema construído), por exemplo, a infraestrutura dos bairros. E por último, as características pertencentes à superestrutura da sociedade (economia, política) e a cultura da população que a constitui, além da educação e da tecnologia (subsistema social). O subsistema social é a atribuição dos aspectos sociais que configuram o uso e ocupação sobre o sítio urbano (MENDONÇA, 2004).

O acoplamento destes dados foi trabalhado no Google Earth, pontuando as áreas identificadas como propícias ao desenvolvimento do Aedes aegypti, em seguida, foi realizado o mapeamento destes dados no Arqgis, a fim de evidenciar em quais contextos urbanos e fatores/potencializadores contribuíram na formação de áreas vulneráveis ao risco de dengue.

\section{SISTEMA AMBIENTAL URBANO (S.A.U.): APORTE TEÓRICO-METODOLÓGICO NA ANÁLISE DE ÁREAS VULNERÁVEIS AO RISCO DE DENGUE}

Mendonça (2004) considera que uma abordagem integrada dos riscos e as vulnerabilidades socioambientais urbanas, como o exemplo da dengue, apresentam uma articulação entre o conhecimento do sítio urbano e da qualidade de vida a ele associada. Em sua análise, e buscando apontar novas perspectivas metodológicas para os estudos relativos à problemática socioambiental urbana, considerou a cidade como um sistema dinâmico e propõe o S.A.U. (Figura 1), como perspectiva compreensiva e metodológica para o estudo dos problemas socioambientais urbanos (MENDONÇA, 2004a).

Os problemas socioambientais urbanos (por exemplo, a dengue), advindos por meio do processo de produção e reprodução do espaço urbano (PEREIRA, 2009), requer uma análise multicausal, um alicerce teórico-metodológico que consiga abarcar a totalidade destes problemas, por isso a aplicação do S.A.U. neste estudo, pois trata a cidade em sua totalidade por meio de seus três subsistemas, o natural, social e construído.

Figura 1 - Adaptação do uso do S.A.U. ao estudo da dengue em Iranduba.

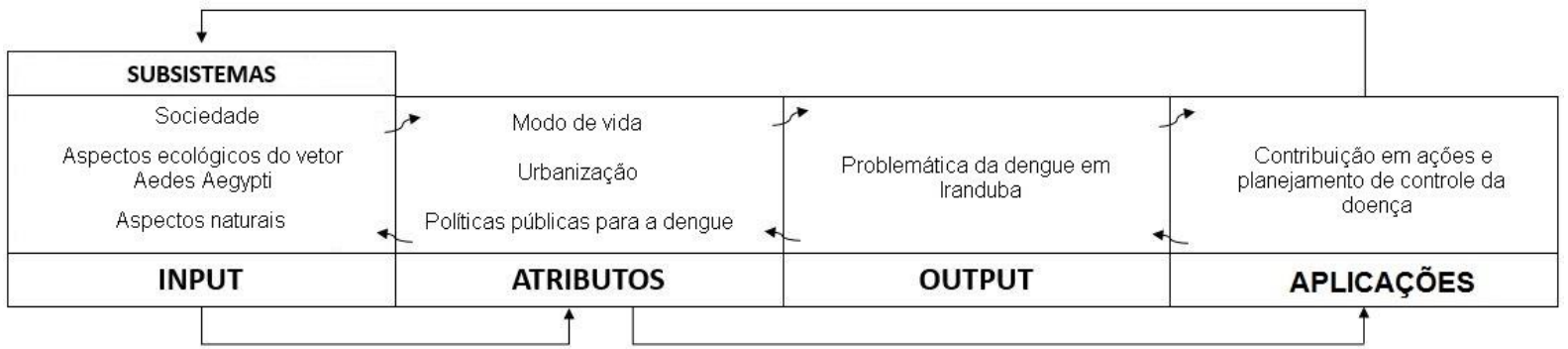

Fonte: Mendonça, 2004. 
A aplicação destes subsistemas concebe o ambiente urbano a partir da interação sociedade (com seus subsistemas: habitação, indústria, comércio e serviços, transporte, lazer) e natureza (por meio de seus subsistemas naturais: relevo, ar, água, vegetação, solo, clima).

\section{RESULTADOS E DISCUSSÕES}

\section{ASPECTOS DOS SUBSISTEMAS NATURAL E CONSTRUÍDO: ESPACIALIDADE URBANA DE IRANDUBA}

A cidade de Iranduba está a $22 \mathrm{~km}$ da capital Manaus. O clima se caracteriza, conforme Koppen, como equatorial, sendo chuvoso e úmido (Af), com média de temperatura anual em $27^{\circ} \mathrm{C}$, sendo que a maior incidência de chuvas ocorre entre novembro e maio (NOBRE, 2009). Deve-se levar em consideração a configuração do relevo e topografia própria do lugar na gestão urbana, os lugares com topografia plana e melhor drenados são alvo dos interesses do mercado imobiliário, em oposição aos lugares que recebem inundações e alagamentos e com topografia não plana e às margens de rios e igarapés, a desconsideração destes aspectos citados e a falta de infraestrutura da cidade geram impactos na análise e na gestão urbana.

Iranduba pela sua proximidade de Manaus e por sua conectividade com a capital ampliada pela Ponte Rio Negro (Figura 2), está tendo um amplo processo de transformação de seus ambientes. A diversidade destas transformações indica a valorização/desvalorização de determinadas estruturas espaciais, assim como a desvalorização de áreas adjacentes (próximas às margens do rio ou barrancos) que se constituíram em favelas, o que o Instituto Brasileiro de Geografia e Estatística (IBGE, 2010) identifica como ambientes subnormais, que segundo Carlos (2008), são terrenos onde não vigora a propriedade privada da terra, onde se configura a autoconstrução, e:

Concomitantemente, com o aumento de moradias, quarteirões e bairros, o poder público não aumenta sua capacidade de ação em tais lugares com o serviço de saneamento básico, postos de saúde e escolas, por exemplo. Com tal ausência, cria-se uma "infraestrutura" contraditória, pois ela favorece a reprodução de mosquitos causadores de enfermidades oriundas da expansão e da produção de espaços urbanos desprovidos de controle de enfermidades. (CARLOS, 2008, p.70).

Figura 2 - Ponte Rio Negro entre a capital Manaus e o município de Iranduba.

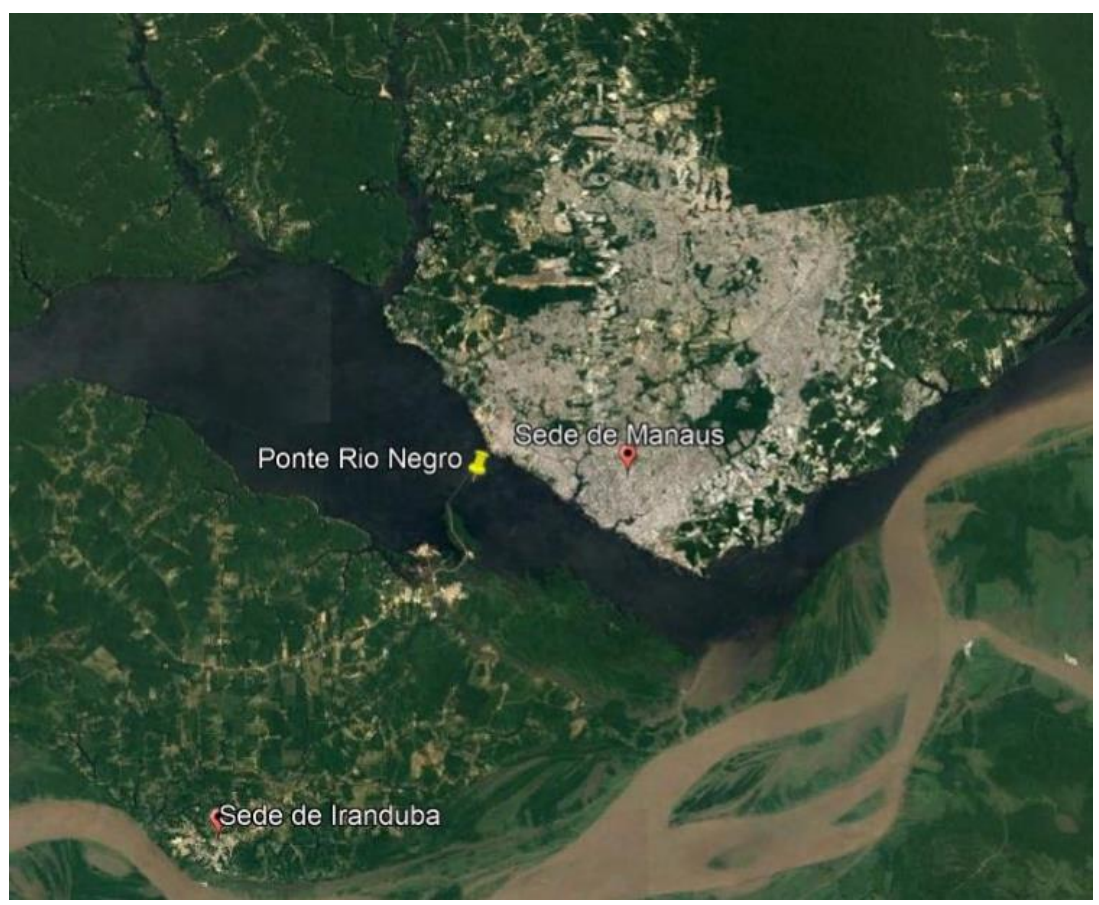

Fonte: Google Earth, 2018. 
A dinâmica das relações sociais e dos processos naturais ocorre de diferentes maneiras, porém interagem no espaço, onde a moradia é uma mercadoria, pois questões como o conforto e segurança pesam em um preço que nem todas as classes de renda possuem condições de pagar. Aqueles que não possuem condições de acesso em um bairro estruturado urbanisticamente são induzidos pela própria lógica do mercado a ocupar áreas sem qualquer infraestrutura, muitas vezes susceptíveis as transformações ambientais (CASSETI, 1991).

Sousa (2013) identifica que a relação de Iranduba com Manaus auxilia na identificação das transformações socioespaciais, a qual acontece associada ao processo acelerado da urbanização, por meio dos investimentos do capital no setor mobiliário, este que já produziu amplas mudanças na paisagem da cidade.

A Figura 3 indica a evolução da espacialidade urbana em Iranduba nos últimos 31 anos. As mudanças na paisagem ocorreram principalmente no Distrito de Cacau Pirera (norte da cidade) e no bairro Centro (sul da cidade), como é identificado na última imagem referente ao ano de 2015 (D). No que diz respeito à demografia do município, este teve um aumento acentuado na população urbana comparada ao rural nos anos de 1991 e 2010, mas isso devido à contribuição da mudança de classificação do distrito Cacau Pirera de rural para urbano (SEPLAN, 2010) assim como a migração de moradores de Manaus para Iranduba. Em 1991, 6.403 habitavam a população urbana, 12.473 na população rural; em 2000, 9.940 na população urbana e 22.363 na população rural, e em 2010 a população urbana passou a ter 28.979 habitantes e 11.802 habitantes no rural (IBGE, 2010).

Figura 3 - Evolução da espacialização urbana em Iranduba.
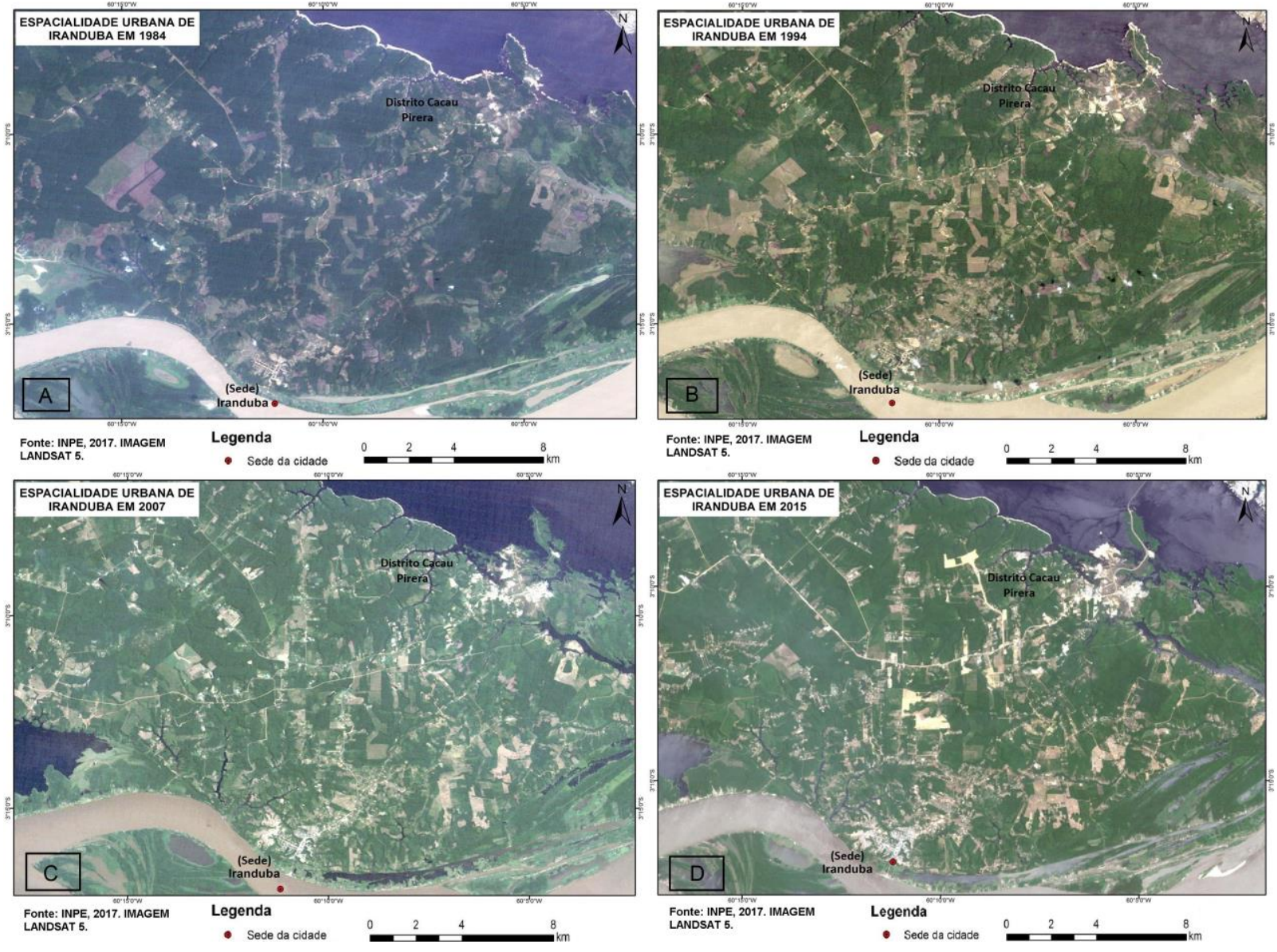

Fonte: INPE, 2017.

Lousada e Santos (2016) e Souza (2013) apontam que a construção da ponte Rio Negro interligou principalmente a zona central de Manaus com a cidade de Iranduba, e ainda favoreceu o aumento da exploração de argila para a construção civil de Manaus, todavia, possibilitou principalmente a 
especulação do setor imobiliário em dominar e apropriar-se de novas áreas (especialmente as áreas que não são alagáveis, de topografia firme e plana), e assim, contribuindo com o crescimento da espacialidade urbana da capital (Manaus) em direção a Iranduba.

No entanto, os valores cobrados nos condomínios (principal investimento na cidade) são altos, o público alvo são os de maior poder aquisitivo, poucos podem pagar por tal conforto estrutural, parte da população não tem acesso a uma moradia com estrutura adequada, principalmente de circulação de águas, o que pode ser identificado nas tipologias das casas, na morfologia das ruas. Os poderes públicos, quando resolvem construir moradias destinadas à classe social de menor poder aquisitivo, constroem habitações metricamente reduzidas e em áreas com poucos, precários ou sem equipamentos urbanos.

Tem-se o exemplo de Cacau Pirera, as residências são atingidas pela subida das águas do rio Negro (Figura 3, D), nesta área foi identificado o aumento da espacialidade urbana bem como a precariedade dos serviços de saneamento básico que não atendem toda a população. $O$ crescimento da cidade com ocupação multidiferenciada dos sítios frágeis e vulneráveis provoca profundas modificações estruturais e de infraestrutura que expõem consideráveis grupos sociais e de renda, principalmente os mais pobres, em condições de risco, devido ao valor do solo e do mercado imobiliário.

\section{SUBSISTEMA SOCIAL DE IRANDUBA: INDICADORES SOCIAIS NA ANÁLISE DE DENGUE}

No que diz respeito à situação da dengue em Iranduba, segundo o SINAN (2016), os primeiros casos foram registrados no ano de 2001 com 30 notificações, no ano de 2011 foram registrados 152 notificações, em 2013 foram 22 notificações, os demais anos tiverem registros abaixo de 16 notificações. Em 2011 a distribuição dos registros de dengue concretizou 90\% entre os meses fevereiro, março, abril e maio, principalmente os dois primeiros meses mencionados, corroborando com os meses mais chuvosos (281 e 301 milímetros) e temperaturas elevadas (30.6 ํㅡ). Infelizmente os dados sobre a doença em Iranduba não são precisos, o que dificulta uma análise mais completa.

A Tabela 1 é referente ao Reconhecimento Geográfico (RG) realizado no ano de 2016 pela Secretaria de Saúde (SEMSA) da cidade. Este tem como finalidade fazer um levantamento da situação social e ambiental para identificar depósitos potencializadores no desenvolvimento da dengue em cada bairro, e assim, evidenciar espacialmente a vulnerabilidade dos grupos sociais à doença. Neste RG são identificados principalmente terrenos baldios, caixas d'água e poços desprotegidos. Há também a classificação de Pontos Estratégicos ou P.E.s, que se referem aos domicílios que possuem serviços prestados como oficinas de borracharias, sucatas, cemitérios, entre outros, a periodicidade da fiscalização, ocorre a cada 15 dias para a eliminação de larvas.

Dentre os criadouros identificados na Tabela 1 pela SEMSA, também foi elaborado na mesma tabela o percentual dos indicadores de saneamento básico, entre estes, água encanada; percentual de domicílios com abastecimento de água e esgoto sanitário inadequado; percentual de domicílios com coleta de lixo, obtidos por meio do censo 2010 do IBGE. Por meio desta organização de indicadores do IBGE e criadouros identificados pela SEMSA, foi possível fazer uma análise mais completa do perfil socioespacial vulnerável a dengue.

Com base na Tabela 1, na coluna referente aos habitantes, os bairros Colônia Cacau Pirera, Nova Veneza e Morada do Sol eram os mais populosos, sendo 6.203, 5.339 e 5.138 habitantes, respectivamente. Posteriormente a estes bairros, os segundos mais populosos foram Bairro Alto com 4.442 habitantes, Alto de Nazaré com 3.905 habitantes, em seguida Novo Amanhecer com 2.838 habitantes, Cidade Nova com 2.362 habitantes, Cidade Nova do CP com 1.645 habitantes, Comunidade São José com 1.532 habitantes e por último São Francisco com 1.508 habitantes. Os menos populosos foram Graça Lopes com 122 habitantes, em seguida Laranjal com 492 habitantes, Parque Caboclo com 615 habitantes e o bairro Centro, com 819 habitantes.

$\mathrm{Na}$ coluna referente à variável terreno baldio, os bairros que mais apresentaram potencialidade de criadouro do vetor foram Nova Veneza com 192, em seguida Graça Lopes com 168, depois o Bairro Alto com 132, posteriormente Novo Amanhecer com 119 e, por fim, Morada do Sol com 112. O bairro Centro é o que apresentou menor número (7), totalizando 1.062 terrenos baldios na cidade de Iranduba, conforme identificado na tabela. 
Tabela 1 - RG dos criadouros de dengue e situação de saneamento básico segundo o censo de 2010 em Iranduba.

\begin{tabular}{|c|c|c|c|c|c|c|c|c|c|}
\hline $\begin{array}{l}\text { Nome do } \\
\text { Bairro }\end{array}$ & Habitantes & \begin{tabular}{|c|} 
Total \\
de \\
terreno \\
Baldio
\end{tabular} & \begin{tabular}{|c|} 
Total de \\
Pontos \\
Estratégicos
\end{tabular} & $\begin{array}{c}\text { Total de Cx. } \\
\text { d'água } \\
\text { desprotegida }\end{array}$ & $\begin{array}{c}\text { Total de } \\
\text { poço } \\
\text { desprotegido }\end{array}$ & $\begin{array}{c}\text { Domicílios } \\
\text { com água } \\
\text { encanada } \\
(\%)\end{array}$ & $\begin{array}{l}\text { Domicílios com } \\
\text { abastecimento } \\
\text { de água e } \\
\text { esgoto sanitário } \\
\text { inadequado (\%) }\end{array}$ & $\begin{array}{c}\text { Domicílios } \\
\text { com } \\
\text { coleta de } \\
\text { lixo }(\%)\end{array}$ & $\begin{array}{c}\text { Renda } \\
\text { per } \\
\text { capita } \\
(\mathrm{R} \$)\end{array}$ \\
\hline $\begin{array}{l}\text { Alto de } \\
\text { Nazaré }\end{array}$ & 3.905 & 34 & 8 & 338 & 21 & 63,83 & 21,44 & 92,12 & 311,55 \\
\hline Bairro Alto & 4.442 & 132 & 8 & 359 & 2 & 95,61 & 39,03 & 91,62 & 367,09 \\
\hline Centro & 819 & 7 & 1 & 94 & 0 & 91,74 & 39,03 & 91,62 & 311,55 \\
\hline $\begin{array}{l}\text { Cidade } \\
\text { Nova }\end{array}$ & 2.362 & 50 & 5 & 260 & 3 & 98,44 & 39,03 & 91,62 & 367,09 \\
\hline $\begin{array}{l}\text { Cidade } \\
\text { Nova do CP }\end{array}$ & 1.645 & 60 & 2 & 86 & 3 & - & - & - & - \\
\hline $\begin{array}{l}\text { Colônia } \\
\text { Cacau } \\
\text { Pirera }\end{array}$ & 6.203 & 42 & 8 & 446 & 17 & 96,21 & 21,44 & 92,12 & 311,55 \\
\hline $\begin{array}{l}\text { Comunidade } \\
\text { São José }\end{array}$ & 1.532 & 51 & 3 & 124 & 8 & - & - & - & - \\
\hline $\begin{array}{l}\text { Graça } \\
\text { Lopes }\end{array}$ & 122 & 168 & 0 & 195 & 1 & 73,45 & 21,44 & 92,12 & 311,55 \\
\hline Laranjal & 492 & 36 & 0 & 68 & 0 & - & - & - & - \\
\hline $\begin{array}{l}\text { Morada do } \\
\text { Sol }\end{array}$ & 5.138 & 112 & 10 & 591 & 1 & 93,77 & 21,44 & 92,12 & 311,55 \\
\hline $\begin{array}{l}\text { Nova } \\
\text { Veneza }\end{array}$ & 5.339 & 192 & 4 & 351 & 9 & 95,98 & 21,44 & 92,12 & 311,55 \\
\hline $\begin{array}{l}\text { Novo } \\
\text { Amanhecer }\end{array}$ & 2.838 & 119 & 2 & 286 & 2 & 87,88 & 21,44 & 92,12 & 311,55 \\
\hline $\begin{array}{l}\text { Parque } \\
\text { Caboclo }\end{array}$ & 615 & 38 & 1 & 73 & 10 & 91,89 & 21,44 & 92,12 & 311,55 \\
\hline $\begin{array}{l}\text { São } \\
\text { Francisco }\end{array}$ & 1.508 & 21 & 2 & 169 & 0 & 93,9 & 39,03 & 91,62 & 367,09 \\
\hline Total: & 38.058 & 1.062 & 54 & 3.440 & 77 & & & & \\
\hline
\end{tabular}

Fonte: Instituto Brasileiro de Geografia e Estatística (2010) e Secretaria Municipal de Saúde de Iranduba (2016).

Os bairros que apresentaram maior número de Pontos Estratégicos (P.E.) foram: Morada do Sol - 10, Alto de Nazaré, Bairro Alto e Cacau Pirera com 8 PEs. Isso devido a principal funcionalidade que estes bairros possuem na cidade, onde Cacau Pirera e Alto de Nazaré possuem grande área comercial como feiras, oficinas de carro e galpões, estes tipos de serviços fazem parte do cotidiano da cidade. Aspectos já pontuados por Barreto \& Teixeira (1996) e Costa (1999, p.273), eles afiram que é devido "a forma em que se organiza o espaço geográfico dos centros urbanos, o modo de vida de suas populações e os seus reflexos no ambiente, que criam as condições para a proliferação dos vetores".

Em relação a variável Caixa D'água desprotegida, novamente os bairros Morada do Sol (591), Cacau Pirera (446), Bairro Alto (359), Nova Veneza (351), Alto de Nazaré (338), Novo Amanhecer (286), Cidade Nova (260) e São Francisco (169) registraram, respectivamente, maior potencial de criadouro no desenvolvimento do vetor. Os bairros que registraram menor potencialidade de criadouros foram Laranjal com 68, em seguida Parque Caboclo com 73 e Cidade Nova do CP com 86. Em relação a 
variável poço desprotegido, os bairros que mais apresentaram problema com este tipo de criadouro foram Alto de Nazaré com 21, em seguida Cacau Pirera com 17.

O indicador de saneamento percentual de domicílios que possuem água encanada evidenciou forte influência com os números de caixas e poços desprotegidos. Por exemplo, os bairros Alto de Nazaré, Graça Lopes, Nova Veneza e Novo Amanhecer registraram menor percentual de domicílios com água encanada, assim como grande concentração de caixas d'água e poços existentes no bairro, entretanto, estes tipos de reservatórios de água não são bem armazenados, os que tornam criadouros favoráveis ao desenvolvimento do vetor da dengue e maior vulnerabilidade do risco da doença à população residente nestes locais. Este fato foi analisado por Barreto e Carmo (1994, p.07), onde eles argumentam que a ocorrência de dengue, na maioria delas "está estreitamente relacionada com as más condições sociais e econômicas das populações, produzindo diferenciais na sua frequência e distribuição".

Dentre os bairros que registraram percentuais acima de $93 \%$ de domicílios com água encanada, também evidenciaram alto percentual de abastecimento e esgoto sanitário de forma inadequado, 0 que pode ser explicado pelo alto número de caixas e poços (individuais e/ou coletivo) desprotegidos. Segundo a variável água e esgoto inadequado, os bairros que registraram maior percentual foram Bairro Alto, Cidade Nova e São Francisco, sendo 39,03\% de domicílios vulneráveis.

Em Iranduba os serviços de coleta e transporte de resíduos domésticos e comercias e os serviços de limpeza urbana são de responsabilidade da Secretaria Municipal de Limpeza Pública, segundo a Tabela 1, todos os bairros apresentaram domicílios com coleta de lixo acima de $90 \%$. Todavia, não foi possível obter informações referentes aos indicadores de saneamento básico para os bairros Cidade Nova do CP, Comunidade São José e Laranjal, em virtude destes bairros terem se constituídos após o ano de 2011 e não fazerem parte do banco de dados do censo de 2010.

A utilização do indicador renda foi devido à sua relação com a tipologia das estruturas urbanas dos bairros, pois estas refletem a capacidade de resposta dos moradores à doença. Aquino (2010) e Almeida (2012) identificaram relação entre as classes de baixa renda com o perfil da espacialização da dengue e identificação das áreas de riscos. A tipologia dos materiais existentes na construção de uma casa reflete o quanto de renda determinada família tem para investir na infraestrutura da casa.

Diante dos indicadores de saneamento apresentados, os bairros que apresentaram piores percentuais correspondem mais da metade da área urbana de Iranduba, se caracterizam como ambientes potenciais ao desenvolvimento do vetor. Para tanto, as Figuras 4,5 e 6 referem-se ao mapeamento das áreas vulneráveis ao risco de dengue, que apresentam a fragilidade dos indicadores analisados anteriormente na tabela. O mapeamento foi realizado a partir do que foi que identificado nos trabalhos de campo e com a utilização de imagens do Google Earth.

A Figura 4 concerne à identificação de áreas vulneráveis ao risco de dengue em Cacau Pirera e Nova Veneza. Conforme o mapa, as áreas vulneráveis apresentaram concentração em ruas específicas, principalmente em finais ou ponta de ruas. As peculiaridades evidenciadas nas fotos retratam os principais problemas de saneamento básico nestes bairros, onde a má qualidade de vida gera os habitats para a ovulação e consequentemente a espacialização do vetor, principalmente em locais onde as condições sanitárias são deficientes (TEIXEIRA E BARRETO, 2008)

Em Cacau Pirera foram identificados criadouros de mosquito, que são oriundos de problemas de encanamento e alagamentos evidenciados nas fotos $A$ e $B$, o que causou grande quantidade de água empoçada ao entorno das casas, assim como tanques, peças de geladeira e plásticos a céu aberto (foto B), a causa de acúmulo de água nestas áreas são tanto pluviais, fluviais (cheias) e como água de encanamento quebrado, soma-se a isso o desvio de água das casas que fazem parte da rede geral de abastecimento para as casas recém-construídas no bairro que ainda não possuem nenhum tipo de abastecimento de água regulamentar, são as ligações irregulares de água.

A foto $C$ evidencia o tipo de reservatório de água utilizado pela população a céu aberto; foto $D$ - se refere a um P.E., foram encontrados tanques e entulho a céu aberto; foto $E$ - tipo de reservatório para abastecer água, pois ainda não há rede geral de abastecimento nesta rua; nas demais fotos ( $F$, $\mathrm{G}, \mathrm{H} \mathrm{e} \mathrm{I}$ ) identificaram-se nas paredes dos imóveis marcas d'água feitas durante as cheias do rio, e na época de vazante do rio ainda assim é identificado tanto alagações como lixos e descartes ao entorno das casas constituídas nestas áreas. Mesmo que estas áreas não possuem saneamento ou qualquer serviço de saneamento básico, as ocupações foram se estruturando e formando os atuais bairros da cidade. 
Figura 4 - Mapeamento das áreas vulneráveis à dengue nos bairros Cacau Pirera e Nova Veneza, localizados ao norte da cidade.
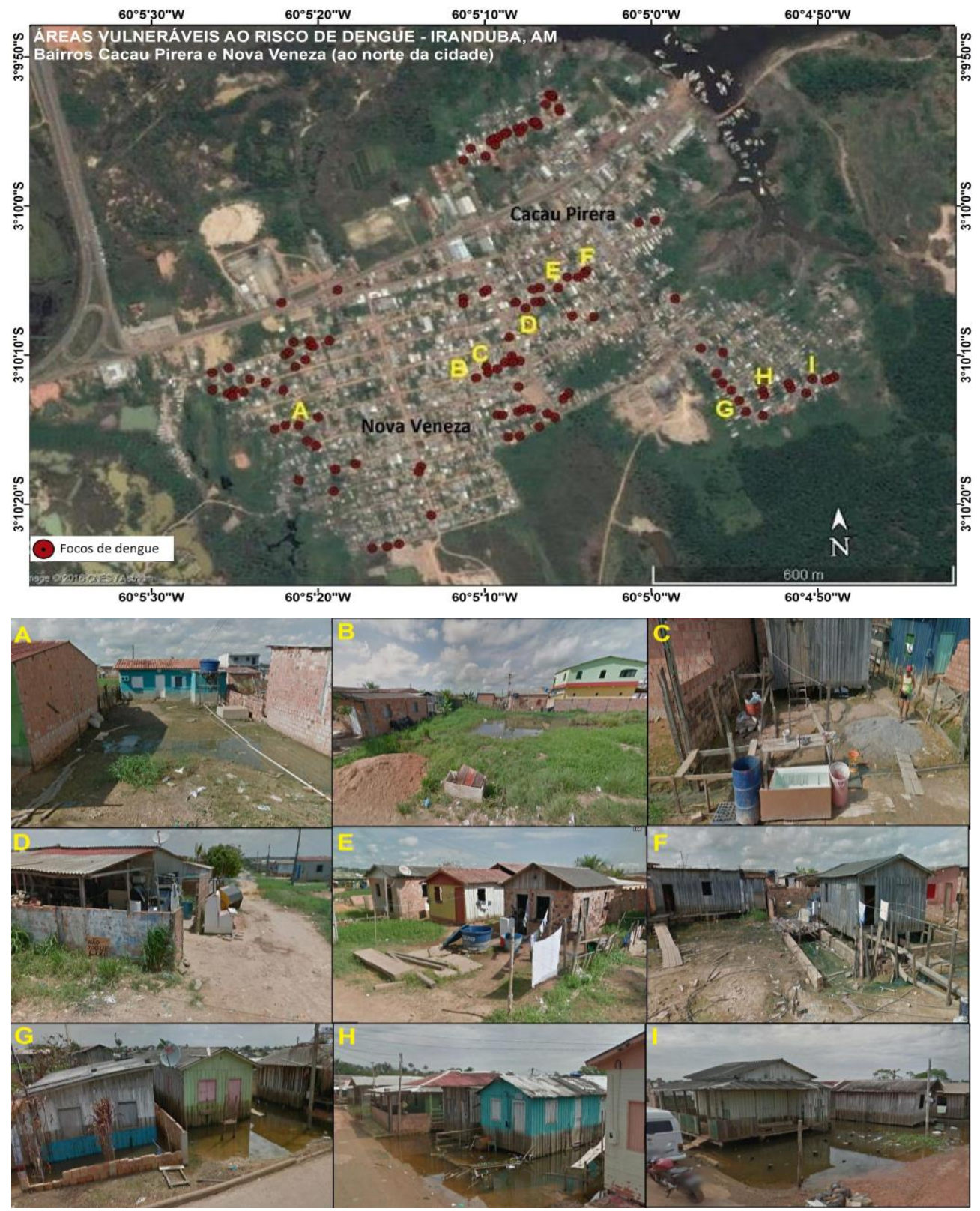

Org. Almeida, R.B (2017).

Em relação à Figura 5, foram identificadas áreas vulneráveis ao risco de dengue nos bairros Parque Caboclo e, sobretudo, no Alto de Nazaré, o qual apresentou maior vulnerabilidade à formação de criadouros de dengue. Nas fotos $A$ e $B$ foram identificados criadouros como água empoçada da chuva juntamente com a cheia do rio Negro no entorno das casas construídas nas zonas periféricas, em áreas inundáveis; $\mathrm{C}$ - o uso de tanques como reservatórios de água descobertos, plásticos utilizado como coberta e há também marcas da enchente do rio na propriedade; $\mathrm{D}$ e $\mathrm{E}$ - formação de lixeira viciada, o que acumula água da chuva e até mesmo arrastada por ela quando intensa e por se concentram em ruas com alta declividade; $\mathrm{F}$ - acúmulo de pneus e peças de carros inutilizáveis. 

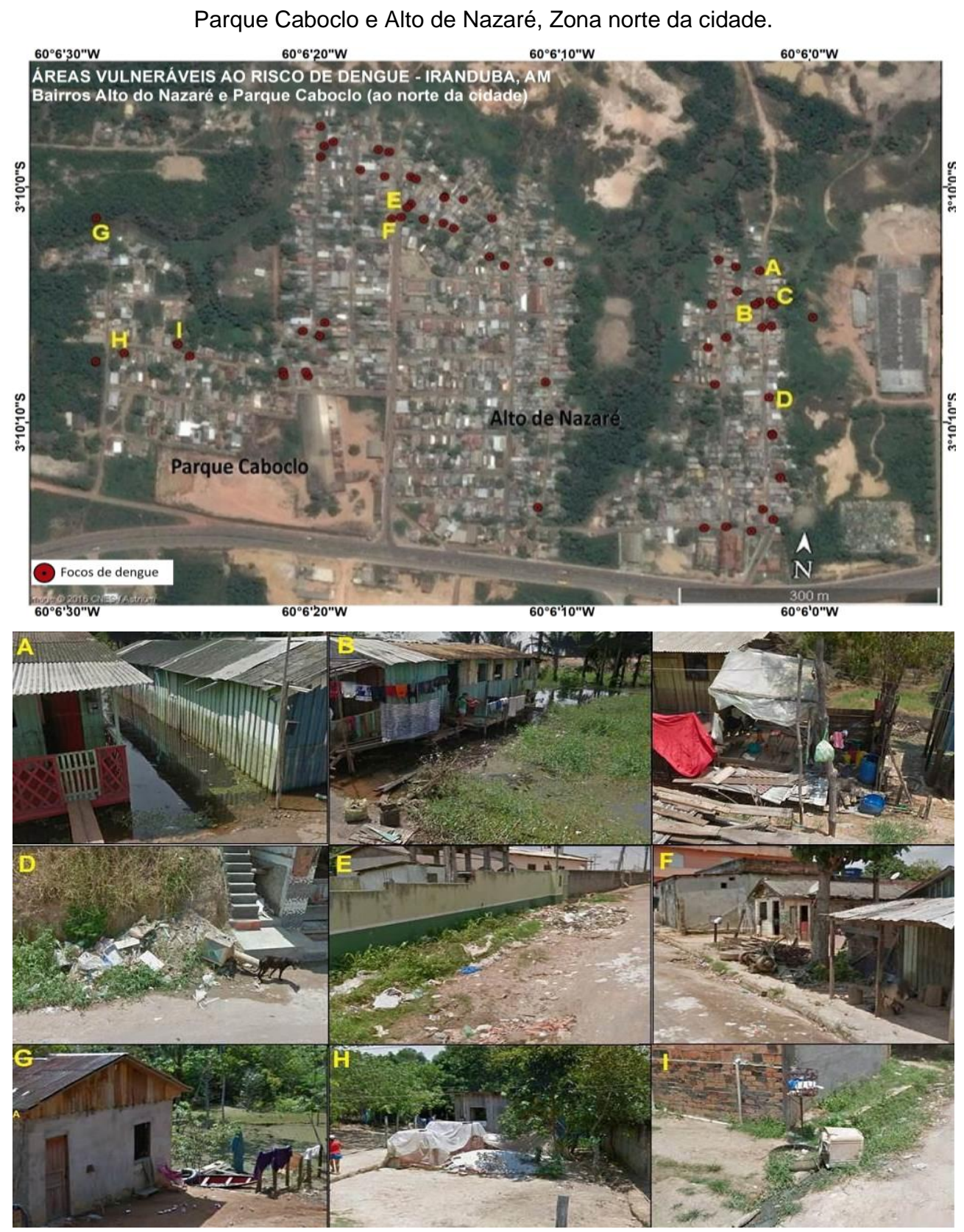

Org. Almeida, R.B (2017).

As demais fotos são do bairro Parque Caboclo, este bairro apresentou forte dinâmica em sua extensão territorial. $\mathrm{Na}$ foto $\mathrm{G}$ foi identificado um reservatório de água descoberto e uma canoa com água parada, nesta área do bairro é comum encontrar canoas devido à dinâmica fluvial, são domicílios construídos em fundo de vale e são atingidos pela enchente do rio. A hidrografia, o clima e o relevo são, muitas vezes, ignorados quando se constitui novos bairros. Conhecer os elementos geomorfológicos do sítio urbano influencia na constituição de moradias, pois mostra às áreas mais propensas à transformação ambiental, mostra quais as áreas mais caras ou mais baratas para se construir, o ordenamento territorial deve ter como requisito, antes de tudo, a sociedade e a natureza.

No bairro Parque Caboclo, na Figura 5, identificou-se muitas casas ainda em construção, por isso, muitos materiais gárbicos e úrbicos foram encontrados cobertos por plásticos, todavia, também acumula água da chuva o que é propício ao desenvolvimento e produção do vetor (foto H). Pneus e tanques de máquina de lavar roupa foram identificados em vários domicílios, este tipo de criadouro é encontrado principalmente em ruas alagadas, com escoamento superficial precário, por isso, a 
consideração da topografia e do clima, especialmente a pluviosidade, pois fazem parte da compreensão e análise das áreas de risco de dengue (foto I).

Os bairros Graça Lopes, Cidade Nova, Morada do Sol e São Francisco, ilustradas na Figura 6, evidenciaram criadouros de dengue com ênfase em caixas/reservatório d'água desprotegidas, identificadas nas fotos $\mathrm{C}, \mathrm{H}$ e I; entulhos, fotos $\mathrm{D}$ e $\mathrm{F}$; encanamento expostos a sol e chuva, que ao serem quebradas por veículos na rua, causam poças d'água, como foi evidenciado na foto $B$; e as chamadas "lixeiras viciadas", evidenciadas nas fotos A, E e G.

Figura 6 - Mapeamento das áreas vulneráveis ao risco de dengue nos bairros Graça Lopes, Cidade Nova, Morada do Sol e São Francisco. Zona sul da cidade

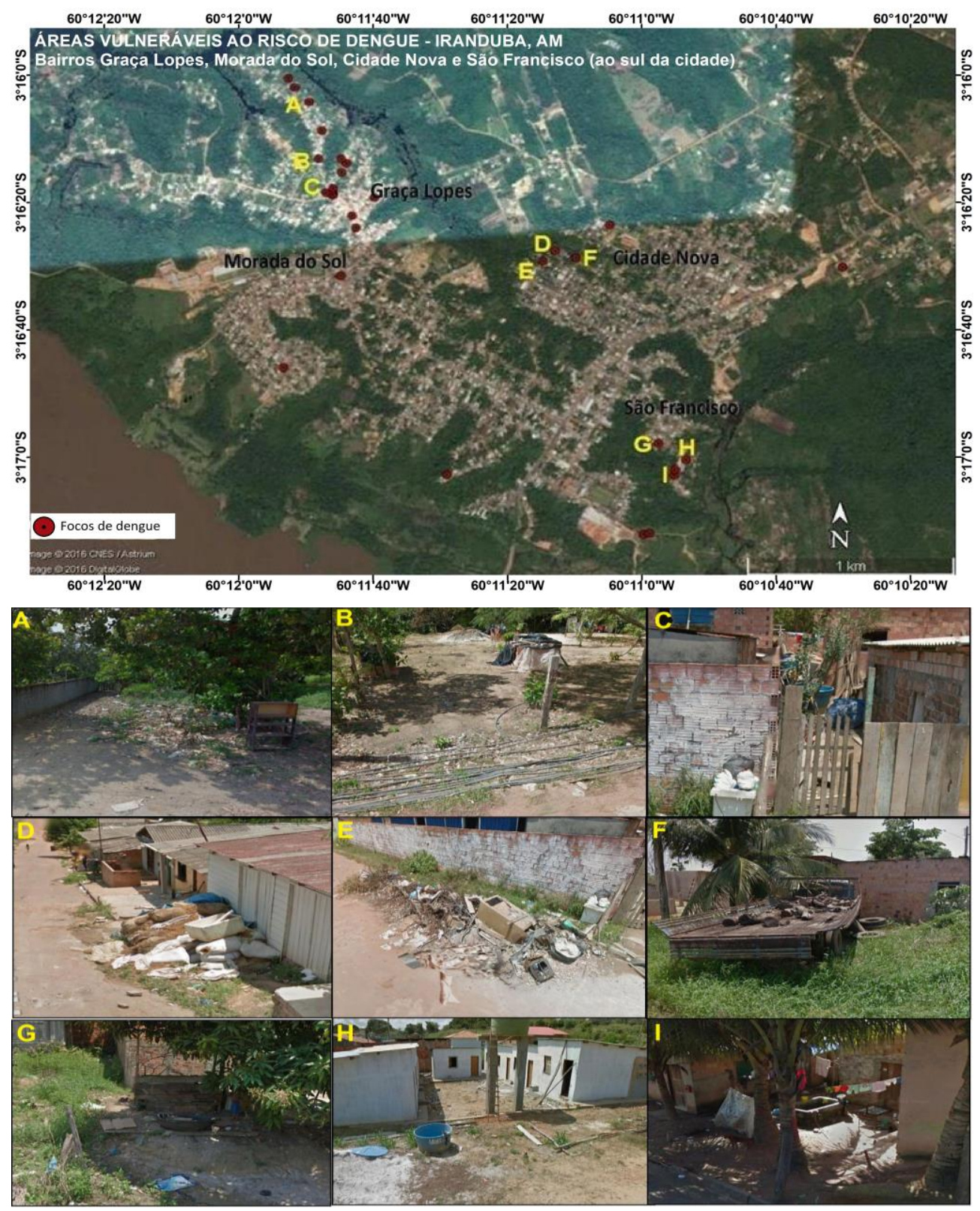

Org. Almeida, 2017.

A formação de áreas vulneráveis ao risco dengue está associada à dinâmica urbana de moradia e serviços. Essas são algumas das "contradições reveladas na lógica de implementação dos padrões de uso e ocupação do solo" (PEREIRA, 2009, p.19), ou seja, o processo de produção do espaço e do meio ambiente construído em Iranduba tornou este lugar um elemento de análise importante para o 
entendimento dos fatores/potencializadores no desenvolvimento da dengue, mesmo em espaços urbanos de pequena escala, como Iranduba.

\section{CONSIDERAÇÕES FINAIS}

Os resultados obtidos e analisados com uso do Sistema Ambiental Urbano identificaram a formação de áreas vulneráveis a dengue, onde o subsistema natural a partir dos elementos: chuva e a topografia, a primeira pela formação de criadouros e a segunda devido ao modo de como esta é apropriada por uma determinada classe socioespacial, e as áreas propícias ao desenvolvimento do vetor estão localizadas em porções menos elevadas, inundadas e com precariedade de infraestrutura urbana.

Por meio do subsistema construído e social identificou-se que as áreas vulneráveis a dengue estão relacionadas à dinamicidade do espaço urbano. As multivariadas formas de apropriação do solo refletem as desigualdades socioespaciais nas infraestruturas urbanas e espacialização de serviços públicos, como saneamento. A constituição de moradias ocorre em áreas susceptíveis às transformações ambientais (como as enchentes) e em áreas com precariedades de estruturas urbanas, como a ineficácia e/ou ausência de saneamento básico (abastecimento de água, coleta de lixo, rede de esgoto) e serviços básicos como a saúde e educação.

Identificou-se também que Iranduba possui mais da metade de seu espaço urbano vulnerável ao desenvolvimento do vetor da dengue, bem como a formação de outras potencialidades a outras doenças. Um aspecto a ser considerado na cidade é a ausência de um banco de dados da doença eficaz, ausência também de estações meteorológicas, visto que há áreas com risco de alagação, que é um dos condicionantes na distribuição espacial da dengue. A instalação de estações meteorológicas é importante tanto para fins de estudos futuros como para o monitoramento constante nas áreas de risco e desenvolvimento de doenças.

A aplicação do S.A.U. tem se revelado como um campo de possibilidades para o entendimento de riscos e vulnerabilidades socioambientais a partir da interação sociedade-natureza, servindo como um aprendizado acadêmico, técnico e para ações políticas, visando de forma sistêmica, multicausal e interativa as soluções ou mitigações de problemas socioambientais urbanos.

\section{REFERÊNCIA BIBLIOGRÁFICA}

ALMEIDA, L. Q. Riscos ambientais e vulnerabilidades nas cidades brasileiras: conceitos, metodologias e aplicações. São Paulo: Cultura Acadêmica, 2012.

ALMEIDA, R. B.; COSTA, R. C. Clima e Região Metropolitana de Manaus: Instrumentos para a análise de dengue e politicas publicas, 2016. Anais do V Congresso de Iniciação Científica do Inpa - CONIC. Manaus, 2016, p.94-99.

ALMEIDA, R.B. COSTA, R. C. A espacialização da dengue e sua relação com o clima na cidade de Manacapuru - AM, Anais do XII Simpósio Brasileiro de Climatologia Geográfica - Variabilidade e Suscetibilidade Climática: Implicações Ecossistêmicas e Sociais. Goiânia, 2016a, p.294-305. Disponível em: <http://www.abclima.ggf.br/sbcg2016/anais/arquivos/eixo_2/trabalho\%20(1).pdf.>. Acesso em 12 jan. 2018.

ALMEIDA, R. B.; CASTRO, M. B.; COSTA, R. C. Dengue na Região Metropolitana de Manaus. In: REINALDO CORREAA COSTA (Org.). Riscos, Fragilidades \& Problemas Ambientais Urbanos em Manaus. Manaus, Editora INPA, 2017, p. 61-84.

AQUINO JUNIOR, J. A dengue na área urbana contínua de Maringá (PR): uma abordagem socioambiental da epidemia de 2006-2007. 15 de abril de 2010. Dissertação de Mestrado em Geografia. Setor de Ciências da Terra. Universidade Federal do Paraná. Curitiba, 2010.

BANDEIRA, A. P. N.; NUNES, P. E. S.; LIMA, M. G. S. Gerenciamento de riscos ambientais em municípios da região metropolitana do Cariri (Ceará). Ambiente \& Sociedade, São Paulo, v. 19, n.4, p.65-84. Out-dez. 2016. Disponível em:

$<$ http://www.scielo.br/scielo.php?script=sci_arttext\&pid=S1414-

753X2016000400081\&lng=pt\&nrm=iso\&tlng=pt>. Acesso em 01 fev. 2017. 
BARRETO, M. L.; CARMO, E. H. Situação de saúde da população brasileira: tendências históricas, determinantes, e implicações para as políticas de saúde. Informe Epidemiológico do SUS, v.3, n.3-4, p. 7-34, 1994. https://doi.org/10.1590/S0103-40142008000300005

BARRETO. M.L; TEIXEIRA, M.G. Dengue no Brasil: Situação epidemiológica e contribuições para uma agenda de pesquisa. Revista Estudos Avançados, v. 22, n.64, p. 53 a 72, 2008.

Disponível em: < http://www.scielo.br/scielo.php?script=sci_arttext\&pid=S0103-

40142008000300005>. Acesso em 22 jan. 2017. https://doi.org/10.1590/1413-812319961101582014

BARRETO. M.L; TEIXEIRA, M.G. Porque devemos, de novo, erradicar o Aedes aegypti. Ciência \& Saúde Coletiva, n.1, p.122-135, 1996.

BELEZA, M.C; COSTA, R.C. O clima urbano e a dengue em Manaus-AM: Correlações e contextos. Anais do V Congresso de Iniciação Cientifica do Inpa - CONIC. Manaus: 2016, p.100106.

BELEZA, M. C.; COSTA, R. C. O clima urbano e a distribuição espaço-temporal da dengue no bairro Cidade de Deus - Manaus-AM. Anais do XII Simpósio Brasileiro de Climatologia Geográfica: Variabilidade e Susceptibilidade climática: Implicações ecossistêmicas e sociais. Goiânia, 2016a, p. 593-604. Disponível em: < http://www.abclima.ggf.br/sbcg2016/anais/arquivos/eixo_2/trabalho\%20(27).pdf>. Acesso em 12 jan. 2018.

BELEZA, M. C.; COSTA, R. C. Clima urbano e a dengue em Manaus-AM. In: REINALDO CORRÊA COSTA (Org.). Riscos, fragilidades \& problemas ambientais urbanos em Manaus. Editora do INPA, Manaus, 2017. p. 31-57.

BELEZA, M. C.; COSTA, R. C. O clima urbano e a distribuição espaço-temporal da dengue no bairro Cidade de Deus - Manaus/AM, 2016. Aanais XII Simpósio Brasileiro de Climatologia Geográfica - variabilidade e suscetibilidade climática: implicações ecossistêmicas e sociais, p. 593604.

BERTRAND, G. Paisagem e geografia física global: esboço metodológico. Caderno de Ciências da Terra, n.13, 1972.

BUENO, N.; LIMA, R. M. B.; AZEVEDO, C. P.. Contribuições de espécies florestais para fins energéticos sobre algumas características químicas de um podzólico amarelo impactado por usos anteriores no município de Iranduba - AM. Embrapa, Manaus, n.11, p. 1-6, 2000. Disponível em: <http: //www.infoteca.cnptia.embrapa.br/bitstream/doc/670826/1/IT112000.pdf.> Acesso em 15. Fev. 2017.

CARLOS, A.F.A. A cidade. (1992) São Paulo: Editora Contexto, 2008. 105 p. Coleção Repensando a Geografia. https://doi.org/10.7154/RDG.1992.0006.0011

CASSETI, V. Ambiente e apropriação do relevo. Revista contexto, São Paulo, p. 147, 1991.

CASSIANO, K. R. M. COSTA, R. C. Identificação das Áreas de Risco de Manaus (AM), Brasil, 2009. Montevideo. Anais do 12 Encuentro de Geografos de America Latina: Caminando em una America Latina en Transformacion. Montevideo, p.1-12.

COSTA, M. C. N.; TEIXEIRA, M. G. A concepção de "espaço" na investigação epidemiológica. Cadernos de Saúde Pública. v.15, n.2, p. 271-279, 1999. https://doi.org/10.1590/S0102-

$\underline{311 X 1999000200012}$

CRUZ, D. R.; CASSIANO, K. R. M.; COSTA, R. C. Áreas de risco em Manaus: Inventário preliminar. Observatorio de la Economía Latinoamericana, n.123, p 1-45, 2009. Disponível em <http://www.eumed.net/cursecon/ecolat/br/>. Acesso em 01 fev. 2017.

DANTAS, R. T.; COSTA, R. C. Riscos e vulnerabilidades associados à dinâmica socioambiental no Bairro Nova Cidade, Manaus - AM. In: REINALDO CORRÊA COSTA (Org.). Riscos, fragilidades \&amp; problemas ambientais urbanos em Manaus. Editora do INPA, Manaus, 2017. p. 82-98.

INTITUTO NACIONAL DE GEOGRAFIA E ESTATÍSITCA (IBGE). Sinopse do Censo Demográfico 2010: Amazonas. Disponível em: <

http://www.censo2010.ibge.gov.br/sinopse/index.php?uf=13\&dados=1>. Acesso em 02 fev. 2017. 
INSTITUTO NACIONAL DE PESQUISAS ESPACIAIS (INPE). Disponível em: <http://www.dgi.inpe.br/catalogo/>. Acesso em 02 fev. 2017.

KOPPEN, W. Classificação climática de Köppen-Geiger. Disponível em: $<$ https://portais.ufg.br/up/68/o/Classifica o_Clim_tica_Koppen.pdf.>. Acesso em 11 outubro 2017.

LOUSADA, C. O.; SANTOS, E. C. Reconfiguração espacial do Munícipio de Iranduba, com a inauguração da Ponte Rio Negro, Amazonas, Brasil. Revista Cesumar Ciências Humanas e Sociais Aplicadas, Maringá, v.21, n.1, p. 29-44, jan./jun. 2016. Disponível em: < periodicos.unicesumar.edu.br/index.php/revcesumar/article/viewFile/4016/2788>. Acesso em: 12 fev. 2017.

MENDONÇA, F. A.; SOUZA, A. V.; DUTRA, D. A. Saúde pública, urbanização e dengue no Brasil. Sociedade \& Natureza, Uberlândia, v.21, n.3, p. 257-269, dez. 2009. Disponível em: < http://www.scielo.br/pdf/sn/v21n3/a03v21n3.pdf>. Acesso em: 12 jan. 2017. https://doi.org/10.1590/S1982-45132009000300003

MENDONÇA, F. A. Aquecimento global e saúde: Uma perspectiva geográfica: Notas introdutórias. Revista Terra Livre, v.1, n. 20, p. 205-221, 2003. Disponível em: <http://www.agb.org.br/files/TL_N20.pdf>. Acesso em 12 jan. 2017.

MENDONÇA, F. A. Riscos, vulnerabilidade e abordagem socioambiental urbana: uma reflexão a partir da RMC e de Curitiba. Desenvolvimento e Meio Ambiente, n.10, p.139-148, jul./dez. 2004. Disponível em: < http://revistas.ufpr.br/made/article/viewFile/3102/2483>. Acesso em: 10 fev. 2017. https://doi.org/10.5380/dma.v10i0.3102

MENDONÇA, F. A. Impactos socioambientais urbanos. Curitiba: Editora da UFPR, 2004a. 328 p.

MENDONÇA, F. A. Geografia, Geografia Física e meio ambiente: uma reflexão a partir da problemática socioambiental urbana. Revista Anpege, Dourados, v.5, p. 123-134, 2009. Disponível em: < http://anpege.org.br/revista/ojs-2.4.6/index.php/anpege08/article/view/35>. Acesso em 20 jan. 2017. https://doi.org/10.5418/RA2009.0505.0010

MENDONÇA, F. A. Riscos e vulnerabilidades socioambientais urbanos: a contingência climática. Mercator, v.9, número especial, p. 153-163, dez. 2010. Disponível em: < http://www.mercator.ufc.br/index.php/mercator/article/viewArticle/538>. Acesso em: 20 jan. 2017.

NOBRE, C. A.; OBREGÓN, G. O.; MARENGO, J. A. Caracteística do clima amazônico: aspectos principais. Amazonia and Global Change, n.186, p.149-162. Disponível em:

https://daac.ornl.gov/LBA/lbaconference/amazonia_global_change/10_caracteristicasNobre.pdf\&ved=0ahUKEwj89LSRmvjWAhVBG5AKHTEZDXoQFghaMAw\&usg=OvVaw3eYVABzVjDiEK5bUrQF-p.>. Acesso em: 16 outubro de 2017.

NUNES, L. H. Urbanização e desastres naturais: abrangência da América do Sul. São Paulo: Oficina de Textos, 2015.

OLIVEIRA, M. M. F. Condicionantes Socio-ambientais Urbanos da Incidência da Dengue na Cidade de Londrina/PR. 2013. Dissertação de Mestrado em Geografia. Universidade Federal do Paraná. Curitiba, 2006.

PAULA, E. V. Dengue: Uma Análise climato-geográfica de sua manifestação no Estado do Paraná. 2005. Dissertação (Mestrado em Geografia) - Universidade Federa do Paraná, Curitiba, 2005.

PEREIRA, F. O. A problemática ambiental urbana: uma avaliação da relação entre o padrão de ocupação e o potencial de degradação ambiental, em trechos de área de Borda Marítima de Salvador-BA. 2009. Dissertação de mestrado em Engenharia Ambiental Urbana. Universidade Federal da Bahia. Salvador, 2009.

PINHEIRO, H. A.; WITKOSKI, A. C. Entre a racionalidade produtiva e a conservação do ambiente: a produção oleira do município de Iranduba e suas consequências ambientais. Revista Latitude, v.5, n.2, p. 49-73, 2011. Disponível em: < http://www.seer.ufal.br/index.php/latitude/article/viewFile/1010/688>. Acesso em: 08 fev. 2017. https://doi.org/10.28998/2179-5428.20110204 
ROCHA, R. L. Antes da chuva e da seca. Revista Radis, n. 135, dez. 2013. Disponível em: http://www6.ensp.fiocruz.br/radis/revista-radis/135./editorial/>. Acesso em: 20 jan. 2017.

ROSEGHINI, W. F. F. Clima urbano e dengue no centro-sudoeste do Brasil. 2013. Tese de Doutorado em Geografia. Universidade Federal do Paraná. Curitiba, 2013.

SECRETARIA MUNICIPAL DE SAÚDE (SEMSA): Iranduba. Boletim de reconhecimento geográfico, 2016.

Secretaria de Estado de Planejamento e Desenvolvimento Econômico. (SEPLAN). 2010. Estimativa populacional para o Estado do Amazonas 2010/2020. Disponível em:

<http://www.seplan.am.gov.br/arquivos/download/arqeditor/estima_populacional_2010.pdf.>. Acesso em: 20 ago.2015.

SISTEMA DE NOTIFICAÇÕES E AGRAVOS (SINAN): Iranduba. 2016. Disponível em: < http://www.portalsinan.saude.gov.br/dados-epidemiologicos-sinan>. Acesso em: 05 jan. 2017.

SOUZA, I. S. A ponte Rio Negro e a Região Metropolitana de Manaus: adequações no espaço urabno-regional à produção do capital. 2013. 249 f. Tese de Doutorado. Faculdade de Filosofia, Letras e Ciências Humanas da Universidade de São Paulo. São Paulo, 2013.

INSTITUTO BRASILEIRO DE GEOGRAFIA E ESTATÍSTICA. IBGE. Aglomerados Subnormais Informações Territoriais. Disponível em:

$<$ https://ww2.ibge.gov.br/home/presidencia/noticias/imprensa/ppts/0000001516481120201348010574 8802.pdf>. Acesso em 11 out. 2017. 